\title{
Simplification of Antiretroviral Therapy (ART)
}

\author{
Maria Paloma Geijo Martinez \\ Internal Medicine, Infectious Disease Department. General Hospital. Cuenca \\ Angel Jesus García Imbroda. Cuenca-1 Health Center. Cuenca \\ Spain
}

\section{Introduction}

Simplification is the change of a therapeutic regimen that has achieved suppression of viral replication by a simpler one that continues this deletion. Its objectives are to improve the quality of life, facilitate adherence and prevent or reverse some adverse effects.

The simplification is achieved by reducing the number of tablets or frequency of shots, to change at the co-formulations, eliminate food, improve side effects and reduce or eliminate interactions.

This strategy was used, with the appearance of the NN. Most initial simplification studies carried out on standards with enhanced PI. RTV boosting with the IP was the first step to develop treatment regimens that do not present problems of complexity and tolerance of the initial PI. The second generation PI and new formulations of old, as well as co-formulations and new classes of drugs have also helped to build simple treatments.

At present the majority of patients starting treatment with simple combinations and subsequently, when they fail, become more complex treatments. Simplification has been a widely used strategy for a long period of time, but now with simple treatment guidelines from the beginning, are standard practice, leaving few for simplicity. ART can be simplified by reducing the number of drugs, the number of tablets or the number of shots.

\section{Reducing the number of drugs}

The first simplification of ART studies were aimed at reducing the number of drugs in what is called induction-maintenance strategy consisting of an initial induction phase with three or four-followed by maintenance with less than three drugs. This strategy was questioned by the failure of some initial trials. Some subsequent studies found no difference in the proportion of patients with $<50$ copies / $\mathrm{mL}(79 \%$ vs. $77 \%)$ at 48 weeks between the branch of simplification and maintenance of initial antiretroviral therapy, adverse reactions were less frequent in the group simplification $(15 \%$ vs. $6 \%)$ and improved lipid profile and adherencia ${ }^{1}$.

He has explored the strategy of simplifying to monotherapy with LPV/r, after a period of induction with triple therapy involving this drug. In a pilot Spanish study comparing, open randomized, that included 42 patients, 21 were simplified to monotherapy with LPV/r. At 72 weeks the proportion of undetectable VL in the monotherapy group was the same $(81 \%)$ and had declined to $90.5 \%$ in the triple therapy group $(p=0.38)^{2}$. In patients who failed were not observed genotypic resistance mutations and re-induced viral suppression NA 
reintroducing the previously recalled. The data at 96 weeks confirmed the durability and safety of this estrategia ${ }^{3}$.

After this study, is performed OK04 study including 205 patients with undetectable VL for at least 6 months (median 28), who were taking HAART including LPV/r associated with two NA. Is a randomized, open, non-inferiority comparing the strategy of continuation of triple therapy compared to monotherapy with $\mathrm{LPV} / \mathrm{r}$, followed by reinduction with $2 \mathrm{NA}$ if viral rebound appeared. At 48 weeks the percentage of patients without virologic failure was 90 and $94 \%$ respectively (difference, $-4 \%$, upper limit $95 \%$ CI for difference $3.4 \%$, meeting the criteria for noninferiority). The percentage of patients with $\mathrm{VL}<; 50$ copies $/ \mathrm{mL}$ at 48 weeks (ITT), considering as failures reinduction was $85 \%$ in the monotherapy group and $90 \%$ in the continuation $(\mathrm{p}=0.31$ ). Episodes of low-level viremia between 50 and 500 copies / $\mathrm{mL}$ were more frequent in patients treated with monotherapy (4 vs. none) ${ }^{4}$.

With patients in these two studies performed a multivariate analysis of predictors of loss of virologic response in the group treated with $\mathrm{LPV} / \mathrm{r}$ monotherapy. Virologic failure was associated with lack of grip, low haemoglobin levels and nadir CD4 $<100$ cells $/ \mu L^{5}$.

In another study of simplification to monotherapy with $\mathrm{LPV} / \mathrm{r}$ was somewhat different strategy. We included 155 previously untreated patients who were randomized 2:1 to treatment with ZDV/3TC start with LPV / r $(n=104)$ or EFV $(n=51)$. Within 24 weeks of treatment and after at least 3 controls with $\mathrm{VL}<50$ copies / $\mathrm{mL}$, patients taking LPV maintenance came to $\mathrm{LPV} / \mathrm{r}$ monotherapy. Whereas failure to any positive viremia at 96 weeks of follow up, $48 \%$ of patients treated with LPV / $\mathrm{r}$ and $61 \%$ with EFV had CVP $<50$ copies / $\mathrm{mL}(\mathrm{p}=0.17,95 \%$ of the difference, $-29 \%$ to $4 \%$ ). In a new analysis that included patients as responders to reintroduce them after getting back NA CVP $<50$ copies / mL, $60 \%$ of patients on $\mathrm{LPV} / \mathrm{r}$ and EFV $63 \%$ responded to treatment $(\mathrm{p}=0.73$, CI $95 \%-19 \%$ $13 \%)$. Have been observed low viral loads in patients on monotherapy. As for security, lipoatrophy was observed in 5\% of the monotherapy arm, compared to $34 \%$ of the EFV group. There were no differences in lipohypertrophy. Grade 3-4 lipid abnormalities were more frequent in the group of LPV/r. In these two studies highlights the importance of the period during which the CVP remains undetectable prior to the step alone.

This same strategy is being explored and DRV $/ \mathrm{r}^{6,7} \mathrm{ATV} / \mathrm{r}^{8,10}$.

They have published the results at 48 weeks of a pilot study, single-arm open-simplification to ATV / r, the ACTG 5201. Were included in the same 34 patients who started treatment with 2 NA and IP, who were with undetectable viral load ( $<50$ copies / $\mathrm{mL})$ for at least 48 weeks, had not been treated with $\mathrm{NN}$ or prior virologic failure were HBsAg negative. Upon entering the study were switched to IP they were taking on ATV / $\mathrm{r}$ and 6 weeks after suspending the AN. The primary endpoint was time to virologic failure. At 48 weeks, 30 patients $(88 \%)$ remained with undetectable viral load. In those with virologic failure were not detected resistance mutations. In addition, analysis of the residual viremia was observed that was not modified in patients in whom there was no virologic failure, but increased progressively in those who were detected from 4-12 weeks before they confirm the failure. More recently, the study reported data OREY. This is a pilot, open, multicenter single-arm and 96 weeks follow-up evaluation of monotherapy with ATV / r. We included 61 patients who were receiving ART, which had had no previous failure $(\mathrm{VL}<50$ copies / $\mathrm{mL}$ at least 24 weeks) and treated with ATV / r 2 NA at least 8 weeks before inclusion. The analysis at 48 weeks, most patients maintained virologic suppression $(79 \%<400$ copies / mL) after switching to monotherapy, the reintroduction of triple therapy was generally satisfactory $(7$ of 9 patients). The development of primary mutations to PIs was rare ${ }^{8}$. 
As for the DRV / $\mathrm{r}$ have been reported in two clinical trials that explore two different scenarios in which explore the efficacy and safety of administration of $\mathrm{DRV} / \mathrm{r}$ alone. MONET study ${ }^{9}$ included 256 patients on antiretroviral therapy with 2 NAs and a NN or a PI / $\mathrm{r}$ with no previous experience with DRV / $\mathrm{r}$ and no history of virologic failure, with undetectable viral load ( $<50$ copies / $\mathrm{mL}$ ) for at least 6 months. They were randomized to either DRV / r $(800 / 100$ QD) $(n=129)$ alone or 2 AN optimized $(n=127)$. This is a noninferiority study in which the primary objective is the time to loss of virologic response (TLOVR). Although the scheduled follow-up is 96 weeks, reported data are for 48 weeks; them confirming the no inferiority of the branch of DRV / $\mathrm{r}$ alone. In the ITT analysis, considering a change of treatment failure, $85.3 \%$ of patients receiving DRV / $\mathrm{r}$ compared to $84.3 \%$ of those taking 2 NA also had undetectable VL (-1; limit 95\% CI: -9.9$)$. As for the emergence of resistance, a patient is detected by branch genotypic evidence of resistance, but phenotypic DRV.

The study design MONOI 10 is different. This is an open randomized clinical trial which included patients who had received antiretroviral treatment for at least 18 months, who had VL of \&lt;400 copies / $\mathrm{mL}$ during the 18 months before and $\mathrm{VL}<50$ copies / $\mathrm{mL}$ at the time of inclusion, who had not had virological failure to IP and had never received DRV / r. It consists of two phases, first introduced in the treatment DRV/r and 8 weeks later (second phase) were randomized 1:1 to DRV / r (600/100 mg BID) or DRV / r (600/100 BID) + 2 AN. It is a non-inferiority study of the pattern of monotherapy versus triple therapy with the primary goal is the percentage of patients who maintained virological response at week 48 , although the scheduled follow-up is longer. In the initial phase included 242 patients, 226 were randomized. Data have been reported at 48 weeks (110 patients on triple therapy and 109 with DRV / r). In the per protocol results DRV / r alone shows non-inferiority versus triple therapy $(94.1 \%$ vs. $99.0 \%$ of CVP $<50$ copies / $\mathrm{mL})$. In the ITT analysis similar results $(87.5 \%$ vs. $92 \%)$.

Three virological failures were observed (> 400 copies / $\mathrm{mL}$ ) in patients with $\mathrm{DRV} / \mathrm{r}$ alone, undetected for DRV resistance mutations and subsequent viral resupresion after the reintroduction of NA. They review that two patients in the monotherapy group had clinical failure related to suppression of HIV in the central nervous system ${ }^{11}$.

Also presented data from several studies that explore the possibility of another type of induction-maintenance is to initiate treatment with ATV / $r$ and then suspend the RTV. This strategy has been raised given the amount of problems caused by even low-dose ritonavir. The most significant studies are INDUMA and ARIES. The INDUMA is a randomized, open, multicenter, non inferiority, which included 252 previously untreated patients who began treatment with induction $2 \mathrm{AN}+\mathrm{ATV} / \mathrm{r}$ in the week 26-30, which had PVL $<50$ copies / $\mathrm{mL}$ and continued treatment (172) are randomized 1:1 to continue the same treatment or take $2 \mathrm{NA}+$ ATV $400 \mathrm{mg}$ QD followed for 48 weeks 12,13 .

The primary endpoint is the proportion of patients maintaining CVP $<50$ copies / $\mathrm{mL}$ at 48 weeks. Secondary objectives are the percentage of patients with PVL $<400$ copies / mL, CD4 count and data security. Half of the patients had been as a pair of NA ABC/3TC. At week 48, the ATV industry shows no inferiority to the ATV $/ \mathrm{r}$ (proportion of patients with VL of $<50$ copies / $\mathrm{mL}$ is $75 \%$ in the group of ATV/r $(\mathrm{n}=85)$ and $78 \%$ in the field of ATV $(\mathrm{n}=87)$, a difference of 2.9 and a 95\% CI 69.8-15.5). Regarding the safety profile, there were fewer cases of hyperbilirubinemia and dyslipidemia in the ATV industry. The authors conclude that this is a fairly safe option in patients not taking tenofovir. No resistance was detected 
over PI in either arm among patients with virological failure. The study is a study ARIESsimilar. This is an open clinical trial, multicenter, non inferiority which includes patients without prior treatment regimen to which ABC/3TC + ATV / $\mathrm{r}$ and then at week 36 were randomized (1:1) to continue the same treatment or discontinue ritonavir for 48 weeks, if your PVL $<50$ copies / $\mathrm{mL}$ and have not submitted prior virologic failure. 419 patients were randomized and included in the analysis to the 379 (90\%) who completed the 84 week follow up. The primary endpoint was the proportion of patients with $\mathrm{VL}<50$ copies / $\mathrm{mL}$ at week 84 (TLOVR). The authors note that the effectiveness of both treatments is similar, sustained regardless of the CVP at baseline, virological failure is uncommon (2\%).

\section{Reducing the number of tablets and / or dose}

Reducing the number of tablets and / or dose is achieved by replacing the IP by a drug from another group. In this strategy, widely studied, has been evaluated to replace the PI / $\mathrm{r}$ for EFV, NVP or ABC and the other PI / $\mathrm{r}$ can be administered in QD.

\subsection{Simplification with EFV}

There have been many studies about it, but few are comparative. In studies DMP-049 and 027 were randomized patients who were taking HAART with PI to continue with the same or substitute EFV. In both virologic failure was lower in the group EFV 14,15.

Another study compared the change of PI to EFV $(n=25)$, NVP $(n=26)$ or continue with the PI $(n=26)$, in patients on ART with PI, CD4> 300 cells / microL and CVP $<80$ copies / mL maintained over 9 months. At 48 weeks (ITT) there was no difference in the proportion of patients with undetectable VL with EFV $(80 \%)$ or IP $(77 \%)^{16}$.

In a combined study design (case-control and randomized), we compared outcomes of 167 patients (who after discontinuation of IP were randomized to EFV or ABC), with another 167 patients who continued with IP (control). At 48 weeks (ITT) $70 \%$ of patients treated with EFV and $54 \%$ had CVP IP $<500$ copies / $\mathrm{mL}(\mathrm{p}<0.05){ }^{17}$.

\subsection{NVP simplification}

Several randomized studies and a study with case-control design that compares to continue with an PI switch to NVP.

In several randomized to continue with the same PI to simplify the treatment or therapeutic efficacy at 24-48 weeks was similar in both arms and showed improved lipid profile ${ }^{18-20}$. In one study there was a greater virological efficacy in the simplification group ${ }^{20}$.In a casecontrol study of a cohort of patients receiving ART in the first IP and replaced by NVP ( $\mathrm{n}=$ 125) or other IP (new formulation of SQV or PI / r, n = 321) was found at 48 weeks that the relative risk of failure due to change of treatment was 5 times higher with IP than with NVP and there were no differences in the risk of virologic failure ${ }^{21}$.

With a different design, in another Spanish study (MULTINEKA) were randomized to 67 patients on stable and CVP $<50$ copies / $\mathrm{mL}$ for at least 6 months to receive LPV / $\mathrm{r}$ with NVP or two AN. At 48 weeks of treatment, virologic failure was not detected in any of the patients. He described a possible benefit in mitochondrial toxicity in patients with NVP22.

NVP is contraindicated as initial treatment in women with CD4>250 cells / uL and in men> 400 risk of severe hepatotoxicity. However, several independent studies agree that is not 
objectified increased hepatotoxicity or rash in patients with NVP is introduced as a strategy of simplification or substitution of toxicity regardless of the number of CD4. These results are very consistent about the number of patients ${ }^{23}$.

\subsection{ABC simplification}

There have been multiple randomized trials and prospective case-control study to examine this strategy. The results are mixed. In one study, therapeutic efficacy was higher in the branch of ABC 24-26. In the other, including the study COLA30305 TRIZAL25, the efficacy was similar, but there was a higher incidence of failures in those patients who had come to take $\mathrm{ABC}$ and had previously taken sub-optim treatments. The study design and commented combined (case-control and randomized) comparing EFV or ABC to PI, 65\% of patients treated with ABC and $54 \%$ of those who continued with PI had VL of $<500$ copies / mL (p $<0.05)$ at 48 weeks.

In another study, 209 patients were randomized to receive ZDV/3TC/ABC in fixed combination with EFV or LPV / r, for 24-36 weeks. Patients who had PVL $<50$ copies / mL in both arms continued ZDV/3TC/ABC only. At 72 weeks 31 and $43 \%$ maintained undetectable VL (ITT), but $34 \%$ and $25 \%$ changed the standard by toxicidad 26 .

Another pilot study included 17 patients after 12 months receiving a stable HAART containing a PI, went to take ZDV +3TC + ABC and TDF co-formulated. At 24 months, all continued with undetectable VL had an improvement in lipid profile and reduction of patients needed lipid-lowering drugs. It also aimed to a significant decrease in levels of DNA proviral27.

Several studies have shown the existence of a high risk of treatment failure and development of mutations when used NA simplification patterns $+3 \mathrm{TC}+\mathrm{ABC}$ and $3 \mathrm{TC}+$ ddI TDF + TDF so are not recommended as a strategy of simplification despite its simplicity.

\subsection{Direct comparison of EFV, NVP and ABC simplifying ART}

The NEFA is a prospective study in which 460 patients were randomized to treatment with 2 NA plus PI with PVL $<200$ copies / mL for $\geq 6$ months ${ }^{28,} 29$ It replaced the PI by NVP ( $\mathrm{n}=$ 155), EFV $(n=156)$ or $\mathrm{ABC}(\mathrm{n}=149) .50 \%, 58 \%$ and $46 \%$ of patients respectively had received previous treatment with one or two suboptimal NA. The therapeutic efficacy (ITT) at 48 weeks (CVP $<200$ copies / $\mathrm{mL}$ ) was similar in the three groups $(77 \%, 72 \%$ and $77 \%, \mathrm{P}=$ NS). Virologic failure was higher in the CBA group $(6 \%, 4 \%$ and $12 \%, P<0.05)$ and occurred in patients who had received suboptimal treatment. These results were confirmed at 3 years. Genotypic analysis of strains from patients with virologic failure showed a higher number of resistance mutations in patients receiving $\mathrm{NA} \mathrm{ABC}^{29}$. The numbers of patients who discontinued treatment because adverse events, was lower in the CBA group $(17 \%, 17 \%$ and $6 \%, \mathrm{p}<0,001)$. Simplification any NN, particularly NVP, produced benefits in lipid profile, reducing non-HDL cholesterol with $\mathrm{ABC}$. Triglyceride levels were reduced in the three arms. Markers of insulin resistance showed a trend toward improvement. However, the alterations in the fat distribution improved.

A cohort study with data from the French Hospital Database on HIV is reproducing the data from the NEFA but in real life. We included 2462 patients followed for 12 months and the first treatment that included a PI; changed the IP for EFV, NVP or ABC. Predictors of regrowth of the CVP were female gender, younger age, previous suboptimal exposure to antiretrovirals, CPV high ddI/d4T use after the change and switch to NVP or ABC (if it had 
received suboptimal treatment). The differences from the NEFA are probably due to differences metodológicas ${ }^{30}$. Comparing the 3 NA simplification (ZDV+3TC+ABC coformulated) vs. the combination of $2 \mathrm{NA}$ (ZDV+3TC co-formulated) plus NVP. In the ITT analysis at 48 weeks there are no significant differences in CVP indetectable ${ }^{31}$.

\subsection{Simplification to Atazanavir}

The ATV is a PI QD dosing, well tolerated, and with good metabolic profile and fewer tablets has a new simplification strategy in which a PI replaces another.

The SWAN is a phase IIIb open-label study in which 419 patients on stable treatment with PI (powered or not) with undetectable VL were randomized (2:1) to ATV $400 \mathrm{mg}$ QD (if taking TDF was prescribed ATV/r 300/100 mg) $(\mathrm{n}=278)$ or continue with the IP $(\mathrm{n}=141)$. At week 48 , virologic failure was lower in that simplified ( $7 \%$ vs. $16 \%, \mathrm{P}<0.01)$. The virologic efficacy was higher in patients who switched from taking a PI unboosted ATV ( $22 \%$ vs. $5 \%, \mathrm{P}<0.001)$ was not different between those continuing with a PI / r, which went from PI/r and ATV (11\% vs. $8 \%, \mathrm{P}=\mathrm{NS}) 429$. Regarding safety, the suspension of treatment was higher in patients in the control group $(21 \%$ vs. $34 \%, p<0,01)$ and lipid profile was improved in the group simplified to ATV. SIMPATAZ and ATAZIP studies confirm the safety and efficacy of this strategy of simplification, in this case changing $L P V / r$ by ATV $/ r$ 32,33 .

The REAL study from which data were presented at 48 weeks, a clinical trial that includes patients in stable antiretroviral therapy for at least 12 weeks that contains a given BID PI, CVP undetectable and lipohypertrophy, which were randomized to continue the same treatment or change the PI to ATV / r 300/100 mg. Inmuno-virologic control was maintained, showed improved lipid profile in the field of ATC but no differences were observed in body composition. ${ }^{34}$.

Another strategy is developed in the trial AI424-067-48 weeks ${ }^{35}$. This is a randomized, open, prospective study that included 246 patients treated with PI / $\mathrm{r}$ with hyperlipidemia and VL $<50$ copies / mL Patients were randomized to switch to ATV (400 MG) on day 1 (immediate change) or maintain their treatment and switching to ATV (400 MG) at 24 weeks (late switch). At 12 weeks both groups maintained a similar virologic control and those patients taking a significant improvement ATV figures for LDL-cholesterol (-15 and $+1 \%, p<0.0001)$. The authors conclude that the change immediately or delayed, a boosted PI or unboosted ATV in patients with hyperlipemia is associated with improvement in lipid parameters without loss of virologic suppression.

\section{Simplifying dosing regimens to once daily in}

The change to a QD regimen simplification is another way in patients who are well controlled. Several trials have proven the validity of this strategy.

In a clinical trial, 355 patients were randomized to continue their ARV therapy or switching to a QD (ddI + FTC + EFV). At week 48 were still undetectable VL, $87 \%$ of the QD arm and $79 \%$ of those who had not changed $(\mathrm{p}<0.05)^{36}$.

In another non-randomized study which included 169 patients, 84 continued their antiretroviral therapy and 85 switched to ddI + TDF + NVP QD; virologic efficacy was good (76 vs. 86\%, ITT), but CD4 lymphocytes decreased in the branch QD with a half decrease of 95 cells $/ \mu \mathrm{L}^{37}$. 
The combination ddI + TDF has demonstrated virological efficacy but poor recovery of CD4 lymphocytes or even declining in number while the CVP is suppressed. This decrease was more evident when given standard doses (full) of ddI 38. The QD dosing regimens containing combination ddI + TDF should be avoided. Doing so should reduce the ddI dose to $250 \mathrm{mg}$ / day in patients over $60 \mathrm{~kg}$ and $200 \mathrm{mg}$ / day for patients below this weight.

With the advent of fixed-dose combinations of NA administered QD has simplified the situation. Clearly, their role in initial therapy and have begun trials to assess its use in simpler systems. The SWEET trial of 234 patients treated for at least 6 months with ZDV + $3 \mathrm{TC}$ (co-formulated) + EFV and CVP $<50$ copies / $\mathrm{mL}$, were randomized to TDF + FTC (coformulated) $+\mathrm{EFV}$ or to follow the same treatment. At 24 weeks there was improvement in haemoglobin levels and lipid profile in the TDF + FTC arm, maintaining the treatment response (VL $<50$ copies / $\mathrm{mL}, 93 \%$ versus $88 \%, \mathrm{P}=0.26$ ). Recently results published 48 week 39,206 patients. $5 \%$ of patients who continued the same treatment and $3 \%$ of patients who switched, discontinued due to adverse effects. No statistically significant differences were observed between the two arms by intention to treat $(85 \%$ of patients who continued treatment versus $88 \%$ who had changed CVP $<50$ copies / $\mathrm{mL}$ ). In the sub study of 100 patients has been performed DEXA fat tissue, it appears that the fat is maintained or increased in patients who switch treatment, but decreased in the group that continues (mean difference $448 \mathrm{~g}, 95 \%: 57-839 \mathrm{~g}, \mathrm{P}=0.025)$. As in other studies, the increase of fat is lower in patients with ZDV and those with less peripheral fat. No differences between groups in terms of renal toxicity. The researchers conclude that changing ZDV / 3TC by TDF / FTC in patients treated with EFV and virological sustained response is safe front the point of virologic view and is associated with an increase in haemoglobin and improvement in lipid parameters and distribution of body fat.

In another open randomized study ${ }^{40}$, with 80 patients with $\mathrm{VL}<50$ copies / $\mathrm{mL}$ and who are treated with ZDV/3TC (+PI or NN), who were randomized to ZDV/3TC / FTC continue or switch to TDF (RECOMB), at week 24 to $85 \%$ of patients treated with TDF / FTC, had PVL $<50$ copies / $\mathrm{mL}$ compared to $80 \%$ with $\mathrm{ZDV} / 3 \mathrm{TC}(\mathrm{p}=0.77$ ). It was also observed a significant increase in limb fat in patients with fat mass $<7.2 \mathrm{~kg}$ at baseline, but also improve LDL cholesterol in the field of TDF / FTC. In 72 weeks data ${ }^{41}$, there has been no virologic failure; (90\% branch TDF / FTC vs. $83 \%$ branch AZT/3TC present CVP $<50$ copies / mL). (P $=0.52$ ), with similar median increase of CD4. In addition, a significant improvement objective, with gradual increase in limb fat, especially if baseline BMI is $>25 \mathrm{~kg} / \mathrm{m} 2$ and have over 5 years AZT/3TC treatment. The analysis was performed according to baseline BMI greater or not than $25 \mathrm{Kg} / \mathrm{m}^{2}$, and the number of years AZT/3TC treatment and in all stages of peripheral fat improvement is statistically significant in the field of TDF / FTC. The authors conclude that it is a safe strategy from the point of immune-virologic and adverse effects view, which improves lipoatrophy and various biochemical parameters (haemoglobin, hematocrit and LDL cholesterol).

Another similar test is the totem of 91 patients with $\mathrm{VL}<400$ copies / $\mathrm{mL}$ and dyslipidemia who were randomized to continue the same treatment or switch to TDF / FTC. In patients who switched showed a significant improvement in lipid profile at 12 semanas ${ }^{42}$. In BICOMBO study, randomized, open, with 335 patients receiving treatment regimen that included 3TC, and virologic suppression for $\geq 6$ months were randomized to replace coformulated with combinations AN ABC +3 TC $(n=167)$ or TDF + FTC $(n=168)^{43}$. The study was designed to assess non-inferiority of both combinations over, or virologic treatment 
failure. In the TDF + FTC, treatment failure was $13.3 \%$ vs. $19.2 \%$ in the $\mathrm{ABC}+3 \mathrm{TC}$, did not demonstrate non-inferiority of $\mathrm{ABC}+3 \mathrm{TC}$ compared to TDF + FTC (95\% - 2\% $14 \%)$. However $\mathrm{ABC}+3 \mathrm{TC}$ demonstrate non-inferiority compared to TDF + FTC in order to virologic failure $(2.4 \%$ vs. $0 \%, 95 \%$ CI $0.05 \%$ to $6 \%)$. Suspensions due to adverse events were $10 \%$ Of ABC +3 TC group vs. $5 \%$ of TDF + FTC group $(\mathrm{p}=0,004)$. Regarding the lipid profile, reductions in total cholesterol, HDL, LDL and triglycerides were higher in the TDF + FTC branch. The peripheral fat, the abnormal kidney functions or bone mineral density increase were similar. Liver toxicity was very low in both groups. By contrast, the immune response was better in the ABC +3TC. Prior determination of HLA B * 5701 might have changed these results.

He has recently published a prospective, randomized, controlled, open, multicenter trial ${ }^{44}$, including patients treated with undetectable VL than those randomized to continue the same treatment or taking EFV + TDF + FTC co-formulated with a follow up to 48 weeks, showing the same efficiency in the two branches. It included 300 patients with PVL $<200$ copies / $\mathrm{mL}$ for $>3$ months and no change in treatment. They were taking stratified as NN or PI and randomized 2:1 to simplify the treatment (taking single tablet) or continue with the same treatment ( 97 patients). The efficacy and safety was determined at baseline and weeks 4, 12, 24, 36 and 48 . We also carried out an assessment of the quality of life and preferences for drugs. At 48 weeks, $89 \%$ of patients with TDF / FTC / EFV vs. $88 \%$ with the same treatment had PVL $<200$ copies / $\mathrm{mL}$ (TLOVR, 95\%) with a difference between branches of $1.1 \%$ (- $6.7 \%$ to $8.8 \%)$, indicating non-inferiority of the branch of TDF / FTC / EFV. $87 \%$ of patients switched to TDF / FTC / EFV vs. $85 \%$ who did not change, CVP had $<50$ copies / $\mathrm{mL}$ : the difference between the two branches of $2.6 \%$ (95\% CI $-5.9 \%$ to $11.1 \%$. Discontinuation rates were similar, although the suspension due to adverse events was higher in the branch of TDF / FTC / EFV (5\% VS 1\%), mainly CNS-related symptoms. No differences regarding glomerular filtration rate, or adherence. There was an improvement in the number of triglycerides in the field of TDF / FTC / EFV ( 20 vs. $3 \mathrm{mg} / \mathrm{dl}, \mathrm{p} \mathrm{=}=0,035)$.

There is a new option to simplify a QD therapy since the publication of the study NODY, because it has demonstrated the efficacy and safety of Nevirapine simplifying administered twice daily to once a day. It is a study lasting 48 weeks, open, randomized, multicenter, which included 298 stable patients who were taking nevirapine twice daily for at least 12-18 weeks and had PVL $<50$ copies / mL. Were randomized to continue the same treatment or change to nevirapine QD. The primary study objective was to assess the hepatic safety of QD treatment, analyzing the proportion of patients with ALT/AST grade 3-4, and second endpoints were the development of clinical hepatitis and inmune-virological and clinical efficacy. The study demonstrated non-inferiority versus per protocol to maintain the initial pattern, with a no inferiority margin of $10 \%$ for hepatotoxicity, which was the primary objective.

A major unresolved issue is whether the impact of not taking a dose of medication due to forgetfulness or failure may be greater in a QD system in a regimen of multiple daily doses in the appearance of resistance mutations ${ }^{45}$. We currently have multiple drugs can be administered once a day, with a half life long enough to avoid this problem.

\section{Other simplification}

With the advent of new drugs with new families, it was possible to simplify the treatment given to patients multicoated. This simplification is not the number of pills but in the way of 
drug administration. This has already been presented studies that ENF is replaced by RAL, maintaining the treatment effectiveness ${ }^{46-50}$. Although most studies are observational, there has been a clinical trial 47 with included 170 patients with HIV resistant to three drug groups and VL $<400$ copies/mL for at least 3 months of treatment with ENF. They were randomized 1:1 to ENF continue or witch to RAL. The primary endpoint was the cumulative proportion of patients with virologic failure defined as CVP $\geq 400$ copies / $\mathrm{mL}$ through week 24. Virologic failure was observed in 1patient per branch. The conclusion is that the change to RAL is effective and well tolerated at 24 weeks, which offers the advantage of simplicity, the same safety profile and you need a longer-term follow-up.

MVC could not be used in the context of simplification, in studies similar to those already made and in these circumstances cannot be performed tropism test.

But simplification cannot be performed if compromising treatment efficacy. As an example, include two clinical trials recently presented, SWITCHMRK 1 and 251 . Two clinical trials are parallel, multicenter, double-blind, randomized studies encompassing virological controlled patients under treatment which included a Lopinavir/r stable, did not exclude patients who had failed other treatment regimens, provided that at the time of inclusion on CVP $<50$ copies / $\mathrm{mL}$ for at least 3 months. Patients were randomized 1:1 to maintain LPV / $\mathrm{r}$ switch to RAL, the same base analogs. Primary objectives were: percentage change in lipid levels at week 12, the proportion of patients with VL of $<50$ copies / $\mathrm{mL}$ at week 24 as well as safety and efficacy at 24 weeks. In SWITCHMRK 2, 355 patients were randomized at RAL and $\mathrm{LPV} / \mathrm{r}$. After the change, the RAL was confirmed to be well tolerated and produced significant improvements in lipid parameters, but did not demonstrate non-inferiority from the viewpoint virology at week 24: 154 of 175 patients (88\%) vs. 167 of $178(93.8 \%)$ had VL $<50$ copies / $\mathrm{mL}$ in groups of RAL and LPV / $\mathrm{r}$ respectively, the observed difference between the two treatments is $-5.8 \%$ (95\% CI: 12.2 to 0.22 , ITT).

Probably these results are due to the inclusion criteria allowed entry into the study of patients with prior virologic failure, and lower genetic barrier of RAL. The teaching of this study is that it must choose well to patients whose treatment is simplified and the simplification strategy to follow.

\section{Simplification of ART. Recommendations summary}

- In patients with no history of prior failure to IP, with undetectable VL at least 6 months and signs or symptoms of toxicity of AN, is possible to simplify the DRV / $\mathrm{r}$ LPV / $\mathrm{r}$ monotherapy (A level).

- If you have not failed prior to NA, PI can be substituted for EFV, NVP. If the patient has received prior suboptimal treatment with NA, no one PI to simplify ABC, (A level).

- Simplification to ABC is contraindicated associated with 3TC and TDF or associated with TDF and ddI. (B level).

- In patients with high cardiovascular risk, the simplification to ATV or ATV/r or RAL can add metabolic advantages (A level).

- In patients at their first PI regimen with undetectable VL, can be simplified to a QD pattern as: $\mathrm{EFV}+\mathrm{TDF}+\mathrm{TCF}$ (or 3TC), $\mathrm{EFV}+\mathrm{ddI}+3 \mathrm{TC}$ (or TDF), or ATV/r or (ATV) + TDF+TCF. (A level)

- ENF-substitution for virological suppressed patients to RAL has been shown effective and safe. (A level) 
- It is important to select well the patients who should be simplified and strategy. The simplification is not possible at the expense of loss of virologic efficacy. You can only raise a simplification if there has been no previous failure of fully active drugs are used to maintain virologic success (A level)

- Other possible simplifications must be performed within clinical trials, in clinical practice (C level).

\begin{tabular}{|c|c|c|}
\hline Strategy & ART & clinical trials \\
\hline \multirow{4}{*}{$\begin{array}{l}\text { Reducing the number of } \\
\text { drugs }\end{array}$} & monotherapy with LPV / r & $\begin{array}{l}\text { OK04 study. Multivariate } \\
\text { analysis }\end{array}$ \\
\hline & monotherapy with DRV / r & MONET. MONOI \\
\hline & monotherapy with ATV / r. & ACTG 5201. OREY \\
\hline & ATV / r., Suspend the RTV & INDUMA. ARIES \\
\hline \multirow{5}{*}{$\begin{array}{l}\text { Reducing the number of } \\
\text { tablets and / or dose }\end{array}$} & Simplification with EFV & DMP-049 and -027 \\
\hline & Simplification with NVP & MULTINEKA. \\
\hline & Simplification with ABC & COLA30305 TRIZAL \\
\hline & $\begin{array}{l}\text { Direct comparison of EFV, NVP } \\
\text { and ABC simplifying ART }\end{array}$ & $\begin{array}{l}\text { NEFA. French Hospital } \\
\text { Database }\end{array}$ \\
\hline & Simplification to ATV / $\mathrm{r}$ & $\begin{array}{l}\text { SWAN. SIMPATAZ. } \\
\text { ATAZIP. REAL }\end{array}$ \\
\hline \multirow{5}{*}{$\begin{array}{l}\text { A QD regimen } \\
\text { simplification }\end{array}$} & $\mathrm{ddI}+\mathrm{FTC}+\mathrm{EFV}$ & $\begin{array}{l}\text { Molina, J Infect Dis } 2005 . \\
\text { Negredo, Antivir Ther } \\
2004 .\end{array}$ \\
\hline & \begin{tabular}{|l} 
ZDV +3 TC (co-formulated) + \\
EFV
\end{tabular} & \multirow{2}{*}{$\begin{array}{l}\text { SWEET. RECOMB. } \\
\text { BICOMBO }\end{array}$} \\
\hline & $\begin{array}{l}\text { TDF + FTC (co-formulated) + } \\
\text { EFV }\end{array}$ & \\
\hline & $\mathrm{EFV}+\mathrm{TDF}+\mathrm{FTC}$ co-formulated & $\begin{array}{l}\text { Martin A, Clin Infect Dis } \\
2009 .\end{array}$ \\
\hline & QD regimen NVP & NODY \\
\hline \multirow[b]{2}{*}{ Other simplification } & ENF is replaced by RAL & CHEER. ANRS 138 \\
\hline & $\begin{array}{l}\text { maintain LPV/r vs switch to } \\
\text { RAL }\end{array}$ & SWITCHMRK 1 and 2 \\
\hline
\end{tabular}

Table 1. Simplification of antiretroviral therapy (ART) 


\begin{tabular}{|l|c|}
\hline Strategy & Significance level \\
\hline $\begin{array}{l}\text { - In patients with no history of prior failure to IP, with } \\
\text { undetectable VL at least 6 months and signs or symptoms of } \\
\text { toxicity of AN, is possible to simplify the DRV / r LPV / r } \\
\text { monotherapy }\end{array}$ & (A level) \\
\hline $\begin{array}{l}\text { - If you have not failed prior to NA, PI can be substituted for } \\
\text { EFV, NVP. If the patient has received prior suboptimal } \\
\text { treatment with NA, no one PI to simplify ABC. }\end{array}$ & (A level) \\
\hline $\begin{array}{l}\text { - Simplification to ABC is contraindicated associated with 3TC } \\
\text { and TDF or associated with TDF and ddI. }\end{array}$ & (B level) \\
\hline $\begin{array}{l}\text { - In patients with high cardiovascular risk, the simplification } \\
\text { to ATV or ATV/r or RAL can add metabolic advantages. }\end{array}$ & (A level) \\
\hline $\begin{array}{l}\text { - In patients at their first PI regimen with undetectable VL, can } \\
\text { be simplified to a QD pattern as: EFV+ TDF+TCF (or 3TC), } \\
\text { EFV+ ddI +3TC (or TDF), or ATV/r or (ATV) + TDF+TCF. }\end{array}$ & (A level) \\
\hline $\begin{array}{l}\text { - ENF-substitution for virologically suppressed patients to } \\
\text { RAL has been shown effective and safe. }\end{array}$ & (A level) \\
\hline $\begin{array}{l}\text { - It is important to select well the patients who should be } \\
\text { simplified and strategy. The simplification is not possible at } \\
\text { the expense of loss of virologic efficacy. You can only raise a } \\
\text { simplification if there has been no previous failure of fully } \\
\text { active drugs are used to maintain virologic success. }\end{array}$ & (A level) \\
\hline $\begin{array}{l}\text {-Other possible simplifications must be performed within } \\
\text { clinical trials, in clinical practice. }\end{array}$ & \\
\hline
\end{tabular}

Table 2. Simplification of antiretroviral 1 therapy (ART). Recommendations summary.

\section{References}

[1] Castagna A, Danise A, Menzo S, Galli L, Gianotti N, Carini E et al. Lamivudine monotherapy in HIV 1 infected patients harbouring a lamivudine-resistant virus: a randomized pilot study (E184V study). AIDS 2006; 20(6):795-803

[2] Pulido F, Arribas J, González-García J, López Aldeguer J, Domingo P, Estrada V, et al. Risk factors for lossof virological suppression at 48 weeks in patients receiving Lopinavir/ritonavir monotherapy in 2 clinical trials comparing $\mathrm{LPV} / \mathrm{r}$ monotherapy vs. triple therapy with LPV/r (OK and OK04 trials). 14th Conference on Retroviruses and Opportunistic Infections, Los Angeles, February 25-28 2007. Abstract 513.

[3] Cameron DW, da Silva BA, Arribas JR, Myers RA, Bellos NC, Gilmore N et al. A 96 week comparison of Lopinavir-ritonavir combination therapy followed by lopinavirritonavir monotherapy versus efavirenz combination therapy. J Infect Dis 2008; 198(2):234-240 
[4] Nunes EP, Santini de OM, Mercon M, Zajdenverg R, Faulhaber JC, Pilotto JH et al. Monotherapy with Lopinavir/Ritonavir as maintenance after HIV-1 viral suppression: results of a 96 week randomized, controlled, open-label, pilot trial (KalMo study). HIV Clin Trials 2009; 10(6):368-374

[5] Gutmann C, Cusini A, Gunthard HF, Fux C, Hirschel B, Decosterd LA et al. Randomized controlled study demonstrating failure of LPV/r monotherapy in HIV: the role of compartment and CD4-nadir. AIDS 2010; 24(15):2347-2354

[6] Arribas JR, Horban A, Gerstoft J, Fatkenheuer G, Nelson M, Clumeck N et al. The MONET trial: darunavir/ritonavir with or without nucleoside analogues, for patients with HIV RNA below 50 copies/ml. AIDS 2010; 24(2):223-230

[7] Valentin MA, Flandre P, Kolta S, Duvivier C, Algarte-Genin M, Ponscarme D, Slama L, Cuzin L, et al. Fat tissue distribution changes in HIV-infected patients with viral suppression treated with $\mathrm{DRV} / \mathrm{r}$ Monotherapy vs $2 \mathrm{NRTI}+\mathrm{DRV} / \mathrm{r}$ in the MONOI-ANRS 136 randomized trial: results at 48 weeks. 17th Conference on Retroviruses and Opportunistic Infections, San Francisco, February 27-March 2 2010. Abstract 721.

[8] Wilkin TJ, McKinnon JE, DiRienzo AG, Mollan K, Fletcher CV, Margolis DM et al. Regimen simplification to atazanavir-ritonavir alone as maintenance antiretroviral therapy: final 48-week clinical and virologic outcomes. J Infect Dis 2009; 199(6):866-871

[9] Rieger A, Banhegyi D, Schmidt W, Arribas JR, Hill A, van Delft, Y, Moecklinghoff C. The MONET trial 96 week analysis: darunavir/r monotherapy versus darunavir/ $\mathrm{r}+$ 2NRTIs, for patients with HIV RNA $<50$ copies/mL at baseline. 18th International AIDS Conference, Vienna, July 18-23 2010. Abstract TBLBB209.

[10] Valentin MA, Flandre P, Kolta S, Duvivier C, Algarte-Genin M, Ponscarme D, Slama L, Cuzin L, et al. Fat tissue distribution changes in HIV-infected patients with viral suppression treated with $\mathrm{DRV} / \mathrm{r}$ Monotherapy vs $2 \mathrm{NRTI}+\mathrm{DRV} / \mathrm{r}$ in the MONOI-ANRS 136 randomized trial: results at 48 weeks. 17th Conference on Retroviruses and Opportunistic Infections, San Francisco, February 27-March 2 2010. Abstract 721.

[11] Curran A, Gutirerrez M, Deig E, Mateo G, Lopez RM, Imaz A et al. Efficacy, safety and pharmacokinetics of $900 / 100 \mathrm{mg}$ of darunavir/ritonavir once daily in treatment-experienced patients. J Antimicrob Chemother 2010; 65(10):2195-2203

[12] Pulido F, Serrano O, Rivero A, Montes ML, Rubio R, López Bernaldo de Quirós JC, et al. Atazanavir/ritonavir en monoterapia como mantenimiento en pacientes con supresión virológica: Análisis primario a las 48 semanas del estudio OREY. 1er Congreso Nacional de Gesida, Madrid, 21-24 octubre 2009. PO-70.

[13] Ghosn J, Carosi G, Moreno S, Pokrovsky V, Lazzarin A, Pialoux G et al. Unboosted atazanavir-based therapy maintains control of HIV type-1 replication as effectively as a ritonavir-boosted regimen. Antivir Ther 2010; 15(7):993-1002

[14] Becker S, Rachlis A, Gill J, DeJesus E, Pierone G, Kirkland L, Koosian S, Farina D, Labriola D, Ruiz N,Bessen L, Villano S. Successful substitution of protease inhibitors with efavirenz in patients with undetectable viral loads: A prospective, 
randomized, multicenter, open-label study (DMP 049). $8^{\text {th }}$ Conference on Retroviruses and Opportunistic Infections, Chicago, February 4-8 2001. Abstract 20.

[15] Katlama C, Stazewsky S, Clumeck N, Arasteh K, Dellamonica P, Molina JM, et al. Successful substitution of protease inhibitors with Sustiva (efavirenz) in patients with undetectable plasma HIV-1 RNA: results of a prospective, randomized, multicenter, open-label study (DMP 006-027). XIII International AIDS Conference, Durban, South Africa, 2000 (Abstract LbPeB7044).

[16] Negredo E, Cruz L, Paredes R, Ruiz L, Fumaz CR, Bonjoch A et al. Virological, immunological, and clinical impact of switching from protease inhibitors to nevirapine or to efavirenz in patients with human immunodeficiency virus infection and long-lasting viral suppression. Clin Infect Dis 2002; 34(4):504-10

[17] Campo RE, Cohen C, Grimm K, Shangguan T, Maa J, Seekins D. Switch from protease inhibitor- to efavirenz-based antiretroviral therapy improves quality of life, treatment satisfaction and adherence with low rates of virological failure in virologically suppressed patients. Int J STD AIDS 2010; 21(3):166- 171.

[18] Maggiolo F, Ripamonti D, Ravasio L, Gregis G, Quinzan G, Callegaro A et al. Outcome of 2 simplification strategies for the treatment of human immunodeficiency virus type 1 infection. Clin Infect Dis 2003; 37(1):41-49

[19] Negredo E, Ribalta J, Paredes R, Ferre R, Sirera G, Ruiz L et al. Reversal of atherogenic lipoprotein profile in HIV-1 infected patients with lipodystrophy after replacing protease inhibitors by nevirapine. AIDS 2002; 16(10):1383-1389

[20] Arranz Caso JA, Lopez JC, Santos I, Estrada V, Castilla V, Sanz J et al. A randomized controlled trial investigating the efficacy and safety of switching from a protease inhibitor to nevirapine in patients with undetectable viral load. HIV Med 2005; 6(5):353-359

[21] Barreiro P, Soriano V, Blanco F, Casimiro C, de la Cruz JJ, Gonzalez-Lahoz J. Risks and benefits of replacing protease inhibitors by nevirapine in HIV-infected subjects under long-term successful triple combination therapy. AIDS 2000; 14(7):807-12

[22] Negredo E, Miro O, Rodriguez-Santiago B, Garrabou G, Estany C, Masabeu A et al. Improvement of mitochondrial toxicity in patients receiving a nucleoside reverse-transcriptase inhibitor-sparing strategy: results from the Multicenter Study with Nevirapine and Kaletra (MULTINEKA). Clin Infect Dis 2009; 49(6):892-900

[23] de Lazzari E, Leon A, Arnaiz JA, Martinez E, Knobel H, Negredo E et al. Hepatotoxicity of nevirapine in virologically suppressed patients according to gender and CD4 cell counts. HIV Med 2008; 9(4):221-226

[24] Katlama C, Fenske S, Gazzard B, Lazzarin A, Clumeck N, Mallolas J et al. TRIZAL study: switching from successful HAART to Trizivir (abacavir-lamivudine-zidovudine combination tablet): 48 weeks efficacy, safety and adherence results. HIV Med 2003; 4(2):79-86

[25] Pulvirenti J, Goodwin D, Slater L. Simplification of protease inhibitor- containing HAART regimens with abacavir maintains viral suppression and favourable adherence in HIV-1 infected adults (COLA30305). 39th Annual Meeting of the Infectious Disease Society of America, San Francisco, october 25-28 2001.Abstract 620 . 
[26] Mallolas J, Pich J, Penaranda M, Domingo P, Knobel H, Pedrol E et al. Induction therapy with trizivir plus efavirenz or lopinavir/ritonavir followed by trizivir alone in naive HIV-1-infected adults. AIDS 2008; 22(3):377-384

[27] d'Ettorre G, Zaffiri L, Ceccarelli G, Andreotti M, Massetti AP, Vella S et al. Simplified maintenance therapy with abacavir/lamivudine/zidovudine plus tenofovir after sustained HIV load suppression: four years of follow-up. HIV Clin Trials 2007; 8(3):182-188

[28] Martinez E, Arnaiz JA, Podzamczer D, Dalmau D, Ribera E, Domingo P et al. Substitution of nevirapine, efavirenz, or abacavir for protease inhibitors in patients with human immunodeficiency virus infection. $N$ Engl J Med 2003; 349(11):1036-1046

[29] Ochoa de EA, Arnedo M, Xercavins M, Martinez E, Roson B, Ribera E et al. Genotypic and phenotypic resistance patterns at virological failure in a simplification trial with nevirapine, efavirenz or abacavir. AIDS 2005; 19(13):1385-1391

[30] Fisac C, Fumero E, Crespo M, Roson B, Ferrer E, Virgili N et al. Metabolic benefits 24 months after replacing a protease inhibitor with abacavir, efavirenz or nevirapine. AIDS 2005; 19(9):917-925

[31] Martinez E, Gatell JM. Considerations on the effectiveness of nevirapine in protease inhibitor-based regimen simplification. AIDS 2007; 21(13):1829-1830

[32] Mallolas J, Podzamczer D, Milinkovic A, Domingo P, Clotet B, Ribera E et al. Efficacy and safety of switching from boosted lopinavir to boosted atazanavir in patients with virological suppression receiving a LPV/r-containing HAART: the ATAZIP study. J Acquir Immune Defic Syndr 2009; 51(1):29-36

[33] Rubio R, Serrano O, Carmena J, Asensi V, Echevarria S, Flores J et al. Effect of simplification from protease inhibitors to boosted atazanavir-based regimens in real-life conditions. HIV Med 2010; 11(9):545-553

[34] Moyle G, Girard JM, Andrade J, Salvato P, Bogner JR, Hay P, et al. Continuation of BID boosted PI vs switch to once-daily ATV/RTV for the management of lipodystrophy: 48 week primary analysis of the 96 week multicenter, open-label, randomized, prospective ReAL study. 17th International AIDS Conference, Mexico DF, 3-8 August 2008. Abstract MOPDB103.

[35] Sension M, ndrade Neto JL, Grinsztejn B, Molina JM, Zavala I, Gonzalez-Garcia J et al. Improvement in lipid profiles in antiretroviral-experienced HIV-positive patients with hyperlipidemia after a switch to unboosted atazanavir. J Acquir Immune Defic Syndr 2009; 51(2):153-162

[36] Molina JM, Journot V, Morand-Joubert L, Yeni P, Rozenbaum W, Rancinan C et al. Simplification therapy with once-daily emtricitabine, didanosine, and efavirenz in HIV-1-infected adults with viral suppression receiving a protease inhibitor-based regimen: a randomized trial. J Infect Dis 2005; 191(6):830-839

[37] Negredo E, Molto J, Munoz-Moreno JA, Pedrol E, Ribera E, Viciana P et al. Safety and efficacy of oncedaily didanosine, tenofovir and nevirapine as a simplification antiretroviral approach. Antivir Ther 2004; 9(3):335-342. 
[38] Barrios A, Rendon A, Negredo E, Barreiro P, Garcia-Benayas T, Labarga P et al. Paradoxical CD4+ T-cell decline in HIV-infected patients with complete virus suppression taking tenofovir and didanosine. AIDS 2005; 19(6):569-575

[39] Fisher M, Moyle GJ, Shahmanesh M, Orkin C, Kingston M, Wilkins E et al. A randomized comparative trial of continued zidovudine/lamivudine or replacement with tenofovir disoproxil fumarate/emtricitabine in favirenz-treated HIV-1-infected individuals. J Acquir Immune Defic Syndr 2009; 51(5):562-568.

[40] Martínez E, Ribera E, Pulido F, Rubio R, Negredo E, Sanz J et al. Early improvement of limb fat content in patients switching from AZT/3TC to FTC/TDF (TVD): a 24 week interim analysis of the RECOMB Trial. 17th International AIDS Conference, Mexico DF, 3-8 August 2008. Abstract MOPDB102.

[41] Ribera E, Martinez E, Clotet B, Estrada V, Sanz J, Berenguer J, et al. 72 week outcomes following switch from AZT/3TC to FTC/TDF (TVD) vs continuing on AZT/3TC. Final results of the RECOMB trial. 5th IAS Conference on HIV Pathogenesis, Treatment and Prevention, Cape Town, July 19-22 2009. Abstract CDB091.

[42] Valantin MA, Bittar R, de TP, Bollens D, Slama L, Giral P et al. Switching the nucleoside reverse transcriptase inhibitor backbone to tenofovir disoproxil fumarate + emtricitabine promptly improves triglycerides and low-density lipoprotein cholesterol in dyslipidaemic patients. J Antimicrob Chemother 2010; 65(3):556-561

[43] Martinez E, Arranz JA, Podzamczer D, Lonca M, Sanz J, Barragan P et al. A simplification trial switching from nucleoside reverse transcriptase inhibitors to once-daily fixed-dose abacavir/lamivudine or tenofovir/emtricitabine in HIV-1-infected patients with virological suppression. J Acquir Immune Defic Syndr 2009; 51(3):290-297

[44] Martin A, Bloch M, Amin J, Baker D, Cooper DA, Emery S et al. Simplification of antiretroviral therapy with tenofovir-emtricitabine or abacavir-Lamivudine: a randomized, 96-week trial. Clin Infect Dis 2009; 49(10):1591-1601

[45] Airoldi M, Zaccarelli M, Bisi L, Bini T, Antinori A, Mussini C et al. One-pill once-a-day HAART: a simplification strategy that improves adherence and quality of life of HIV-infected subjects. Patient Prefer Adherence 2010; 4:115-125.

[46] Towner W, Klein D, Kerrigan HL, Follansbee S, Yu K, Horberg M. Virologic outcomes of changing enfuvirtide to raltegravir in HIV-1 patients well controlled on an enfuvirtide based regimen: 24-week results of the CHEER study. J Acquir Immune Defic Syndr 2009; 51(4):367-373

[47] De Castro N, Braun J, Charreau I, Pialoux G, Cotte L, Katlama C, et al. Switch from Enfuvirtide to Raltegravir in highly treatment-experienced patients: a randomized open label non-inferiority trial, Easier-ANRS 138. 16th Conference on Retroviruses and Opportunistic Infections, Montreal, February 8- 11 2009. Abstract 572.

[48] Gatti F, Matti A, Nasta P, Cologni G, Costarelli S, Carosi G. Switch from enfuvirtide to raltegravir: a simplification option for heavily pretreated patients. 9th International Congess on Drug Therapy in HIV Infection, Glasgow, November 9-13 2008. Abstract P52.

[49] Talbot A, Machouf N, Thomas R, Marcotte S, Therrien R, Lessard B et al. Switch from enfuvirtide to raltegravir in patients with undetectable viral load: efficacy and 
safety at 24 weeks in a Montreal cohort. J Acquir Immune Defic Syndr 2009; 51(3):362-364

[50] Santos JR, Llibre JM, Ferrer E, Domingo P, Imaz A, Molto J et al. Efficacy and safety of switching from enfuvirtide to raltegravir in patients with virological suppression. HIV Clin Trials 2009; 10(6):432-438

[51] Eron JJ, Young B, Cooper DA, Youle M, DeJesus E, ndrade-Villanueva J et al. Switch to a raltegravir-based regimen versus continuation of a lopinavir-ritonavir-based regimen in stable HIV-infected patients with suppressed viraemia (SWITCHMRK 1 and 2): two multicentre, double-blind, randomised controlled trials. Lancet 2010; 375(9712):396-407 


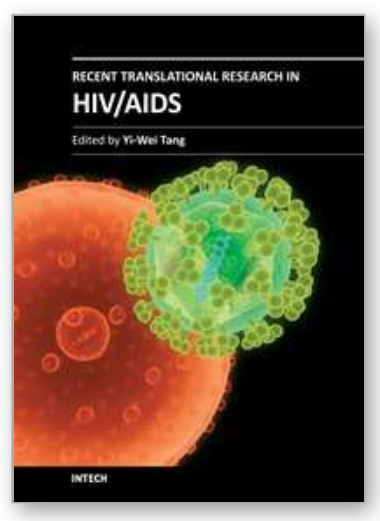

\author{
Recent Translational Research in HIV/AIDS \\ Edited by Prof. Yi-Wei Tang
}

ISBN 978-953-307-719-2

Hard cover, 564 pages

Publisher InTech

Published online 02, November, 2011

Published in print edition November, 2011

The collective efforts of HIV/AIDS research scientists from over 16 countries in the world are included in the book. This 27-chapter Open Access book well covers HIV/AIDS translational researches on pathogenesis, diagnosis, treatment, prevention, and also those beyond conventional fields. These are by no means inclusive, but they do offer a good foundation for the development of clinical patient care. The translational model forms the basis for progressing HIV/AIDS clinical research. When linked to the care of the patients, translational researches should result in a direct benefit for HIV/AIDS patients.

\title{
How to reference
}

In order to correctly reference this scholarly work, feel free to copy and paste the following:

Maria Paloma Geijo Martinez (2011). Simplification of Antiretroviral Therapy (ART), Recent Translational Research in HIV/AIDS, Prof. Yi-Wei Tang (Ed.), ISBN: 978-953-307-719-2, InTech, Available from: http://www.intechopen.com/books/recent-translational-research-in-hiv-aids/simplification-of-antiretroviraltherapy-art-

\section{INTECH}

open science | open minds

\section{InTech Europe}

University Campus STeP Ri

Slavka Krautzeka 83/A

51000 Rijeka, Croatia

Phone: +385 (51) 770447

Fax: +385 (51) 686166

www.intechopen.com

\section{InTech China}

Unit 405, Office Block, Hotel Equatorial Shanghai

No.65, Yan An Road (West), Shanghai, 200040, China

中国上海市延安西路65号上海国际贵都大饭店办公楼 405 单元

Phone: +86-21-62489820

Fax: +86-21-62489821 
(C) 2011 The Author(s). Licensee IntechOpen. This is an open access article distributed under the terms of the Creative Commons Attribution 3.0 License, which permits unrestricted use, distribution, and reproduction in any medium, provided the original work is properly cited. 